potentiation are greater with the milder solution $\mathrm{C}$ than with the stronger solution $\mathrm{B}$.

We are indebted to Sir Stewart Duke-Elder for advice and to the Chief Scientist, the Ministry of Supply, for permission to publish this paper.

\title{
REFERENCES
}

Gilman, A. and Philips, F. S. (1946), Science, Vol. CIII, p. 409.

Halpert, B., German, W. J. and Hopper, E. G. (1933), Amer. J. Physiol. Vol. CIII, p. 351.

Weld, C. B., Feindel, W. H. and Davson, H. (1942), Amer. J. Physiol. Vol. CXXXVII, p. 421.

\section{PERIPHERAL AND CENTRAL DISTURBANCES OF THE VISUAL FIELDS. AN ASPECT OF DI-OPHTHALMOLOGY*}

BY

\section{N. A. Stutterheim \\ JOHANNESBERG}

THE cause of eyestrain, concomitant squint, and amblyopia used to be unknown, the diagnosis incorrect, the therapy inadequate and therefore the prognosis dubious. It was not until convergence had been recognized as the kinetic principle of bi-foveal vision $^{1,2,3,4}$ that the dynamic factor of human binocular vision was established. From then on the diagnosis, prognosis as well as therapy of these disorders could be shaped on rational lines within the precincts of physiology where they belong. These disorders concern the physiology of the bi-foveal eye, the di-ophthalmos, of which the bi-fovea is the highest achievement.

If each of the three following cases were assessed by the usual standards of ophthalmology, they would have a very sombre prognosis. In these cases, there was no workable diagnosis and therefore no therapy, until they could be recognized as disorders of the di-ophthalmos.

\section{Case I}

L., a sctioolboy, aged 17 years, was referred to me by his uncle, a specialist-physician, on July 7, 1946 (abbreviated letter) :-

I- have referred L. du P. to you. His parents are very crincerned as to his condition, and would like to know what the future holds.

\footnotetext{
* Received for publication, March 25, 1947.
} 
Apparently he has had a limited field of vision all his life. At school, less than a year ago, when the eyes were called upon to do very minute work, he had an attack of blindness followed by severe headache, and then an ophthalmic surgeon discovered the real condition of affairs.

What the parents now are anxious to know is:

(1) What is precisely the nature of his complaint?

(2) What is the prognosis-is total blindness to be expected, and within what period?

(3) Will any treatment help or retard the condition ?

(4) Do you advise that he be sent to an Institute for the Blind?

If you think it necessary that a neurologist should also see him, then you are at liberty to make the required arrangements.

L. was brought by his sister because he could not cross the streets by himself. He entered with hands stretched sideways as if feeling for doorposts.

Patient was depressed in his mind. His only desire was not to be examined any more but to go to a school for the blind and learn Braille so as to be able to read and also to learn a trade. $\mathrm{He}$ could read printed matter letter by letter only and a page took him " a whole day." From his first school year onwards he saw as though through a funnel, with both eyes together and with each eye separately. The reason why he had never complained-and so his deficiency had not been discovered earlier-was that he knew no better but that such was the case with everybody else. $\mathrm{He}$ frequently had headaches, often severe ones, sometimes causing him to faint.

Drawing and reading he could not do without strain and headache nor could he go to film shows. He always became giddy when looking out from a moving train. There was no nightblindness and he could orientate himself well when moving about in his home surroundings, even better at night than in daylight.

He could not play the piano with both hands because he could not see them at the same time. Since his tenth year he noticed limitations of his temporal visual fields. This became worse. When thirteen years of age he had an attack of blindness which lasted about an hour, followed by severe headache for the whole day, and he had to retire to bed. He experienced no nausea or giddiness on that occasion.

Similar attacks occurred on four occasions, the last and worst attack being in March, 1946, during a drawing lesson. He had started seeing spots within the narrow funnel of his vision. $\mathrm{He}$ then was sent to an ophthalmic surgeon, and afterwards his uncle 
also examined him. The ophthalmic surgeon sent him to a radiologist and to another specialist-physician. After March he left school altogether.

The boy had difficulty in finding the next letter in each row of Snellen's type, but slowly he could distinguish all the letters of the $6 / 12$ row with each eye.

His fields, taken with a white square of $1 \mathrm{~cm}$., were similar in the right and left eye. They did not extend beyond the 11 degree circle and in some meridians only had 9-7 degrees from the centre-point, but in a circle at $25-30$ degrees distance from the centre-point, flashes of the moving white square were observedwith each eye.

A neuro-psychopathic disposition was excluded (vide infra). Patient was a strong, healthy, intelligent boy. His uncle confirmed this impression and corroborated L.'s story. He further wrote :-

The ophthalmic surgeon consulted (in March, 1946) gave

- a very unfavourable prognosis and, I understand, expressed the opinion that $\mathrm{L}$. was soon to go totally blind.

In July (1946) his mother wrote to me that L. was steadily getting worse and that he himself was very worried that he soon would be blind, and that she had arranged for his admission into the Institute for the Blind at Worcester, and that she had received his railway concession to go there. After this the uncle persuaded the parents to send $L$. to Johannesburg for consultation.

The report on the X-Ray examination read: The examination revealed no enlargement of the pituitary fossa and there was no evidence of increased intra-cranial pressure. The optic foramina were normal.

The second specialist-physician could find nothing positive, and had written accordingly.

It is evident that ophthalmologically nothing had been neglected in order to arrive at a diagnosis, and also that the ophthalmic surgeon was justified in warning the parents as to the seriousness of the condition, as orthodox ophthalmology could give no clue to the real condition. His prognosis was bad: blindness of both eyes, already far advanced, was increasing and, evidently, total blindness impending.

The psychiatrist to whom $\mathrm{L}$. had been referred by me, wrote :-

"I can find nothing that can throw light on the cause of his condition. There is no question of any organic lesion or neurological deviation. Psychologically this patient is perhaps a little tense, but I cannot find any neurotic or psychotic symptoms, and there decidedly is no sign of any inclination to hysteria. I have therefore a perfectly negative report to render. 
I should be pleased to hear the further progress of this interesting case."

In view of the extraordinary features of the case and especially because of the bad prognosis, I asked the opinion of two other ophthalmologists. I showed the letter of introduction by L.'s uncle, the specialist-physician. I refrained from telling them my diagnosis and also that treatment had already been instituted on the strength of that diagnosis. This may explain the slight difference in their and my assessment of visual fields and acuity. He was already more self-confident, as can be seen in the report by one of the two ophthalmic surgeons. It reads as follows:-

Herewith report on L. du P. (July 29, 1946). Examination revealed a normal fundus each side, with visual acuity $6 / 9$ in each eye, with negligible refractive errors. He walked about the place without difficulty, totally unlike a person who had a visual field contraction as is shown on the visual field charts, which I enclose. The visual fields were contracted to 10 degrees (ranging in places to 20 degrees) around the centre-point, with a slight paracentral ring scotoma (relative) within the existing field. Neuro-ophthalmologically I could establish nothing else. Having suspicion that this was a case similar to the case described in your book, I advised him to undergo your treatment.

The other ophthalmic surgeon informed me verbally that he could establish no organic cause for the condition and that it was a case of functional field contraction. His field charts were similar to those of the other doctor and myself. Obviously no adequate diagnosis was made and consequently no rational therapy proposed.

The further progress was that within ten days visual acuity had become normal $(6 / 6)$ in each eye and that within three weeks after the first, a further report by the one consultant, who had kept in touch with the case, reads :-

Examination on August 13, 1946, showed marked improvement in the fields, there being an almost full field, filled in by relative scotoma extending from the periphery up to the region of 25 degrees on an average.

A fortnight later a third report reads :-

Examination on August 29, 1946. Normal fields with small irregular scotomata about 10 degrees from centre-point, O.D.S.

This is a case of similar type to the one described by you, viz., functional peripheral amblyopia. I am sure this cannot be called a hysterically contracted field, and if so, then you have a very effective treatment to offer. If not, which I think is the case, then you have discovered a new condition and its treatment.

In conservative ophthalmology the prognosis of the case of $L$. 
du P. was bad. Conversely my prognosis was good, because the diagnosis is :-

Functional contraction of the visual field of each eye and diminished central visual acuity (amblyopia), combined with various other symptoms of severe eyestrain, caused by asthenovergence.

Initially convergence was low, ranging from "negative" convergence : minus 5 prism degrees to (positive) convergence : 6 prism degrees ; a range, therefore of only eleven degrees of prism (instead of ninety degrees of prism, which can be considered as normal range of reflex-convergence).*

In the first ten sittings of kinetic treatment for astheno-vergence it was rather difficult, technically, to go beyond that range upwards (i.e., to increase the " positive" side of the range) because of the contracted field in each eye, as the second image disappeared too readily in the scotomatous area. Treatment was given twice daily for about ten minutes each time.

Progress was rapid. After thirty-eight sittings of kinetic treatment, the range of convergence was from minus 5 to 91 , the fields and visual acuity were normal and depression of spirit had made place for energy. In six weeks' time $L$. could read fluently. That week and the next, by his own choice, he read a complete popular-scientific book (164 pages). He had himself registered for a two months' course of drawing and modelling, and produced good work there.

Three months after he began treatment he was back at school, making up for lost time.

Altogether eighty-seven sittings of kinetic treatment for asthenovergence had been given during two-and-half months; no other treatment.

\section{Case II}

Another case exemplifying a good prognosis in the light of our knowledge of di-ophthalmology is already on record. It has been described by me in 1937, in the monograph, "Eyestrain and Convergence," pp. 38-41. As, however, this description has apparently passed unnoticed, no mention being made of it, critically, in reviews of the book in the medical press, I feel justified in quoting that chapter (abbreviated).

The title is :-

$$
\text { "Eyestrain with Field Contraction." }
$$

“Another visual symptom of eyestrain that deserves special

* For definitions and the meaning of some terms in di-ophthalmology, see my monographs "Eyestrain and Convergence," pp. 1-16, and "Squint and Convergence, a Study in Di-ophthalmology," pp. 5-9. 
attention is contraction of the visual fields. This disorder in the wake of eyestrain is probably not so rare as our limited experience would seem to suggest. The following case shows that it can assume serious proportions."

In July, 1927, G., a farmer's son, aged twenty-one years, consulted me complaining of frequent headaches and other symptoms of eyestrain of long standing, but his main complaint was some cloudiness in front of his left eye.

Refraction of each eye was normal : a mixed astigmatism of 0.5 dioptre with vertical axis in each eye. Vision of right eye $6 / 4$, of left eye $6 / 9$, with correction (-0.75 D.sph.) 6/4. The fields, as far as a cursory examination revealed, were normal. Ophthalmoscopically or otherwise I could find nothing to account for patient's complaint, except astheno-vergence. Convergence was 12 degrees of prism, negative convergence -5 degrees.

$G$. could not stay for further observation or for treatment, but I saw him again four years afterwards.

In April, 1931, I was again consulted by G., now twenty-five years of age, a farmer of healthy intelligent appearance. He looked tired and complained that for sixteen months now his left eye gave him the impression of looking through a narrow tube, narrower in full light than in the shade or dark. Since boyhood he had suffered from headaches, occasional giddiness and nausea. He experienced discomfort when reading and had largely abandoned it. Moving pictures irritated him and he had given up going to film shows. He wore tinted glasses, slightly cylindrical. They gave relief against glare but made no difference as to his eyestrain. His right eye saw well.

During the period since his former consultation of me, G. had been regularly attended to ophthalmologically elsewhere. Now his general medical attendant wrote to me that: he complains of headaches and failure of vision. . . . His discs look normal and I find no cause for his failure of vision. . . B Beyond testing the peripheral range of vision and finding that it was very deficient, especially in one eye. ...

These quotations from his family doctor's letter show that this was not a neglected case, but that it had received apart from the specialist's help the able and careful attention of the local practitioner.

G. was very concerned about the extreme narrowing of the field of his left eye, stating that sometimes at street corners he bumped into people coming from the left. He was afraid of losing the sight of that eye altogether.

Vision of right eye 6/4 (uncorrected), of left eye 6/9 (uncorrected). Glasses made no improvement. It was difficult to find 
the next letter in the row with his left eye, the right being covered. Refraction : mixed astigmatism 0.5 with vertical axis for each eye.

Perimetric examination with white object $1 \mathrm{~cm}$. square : right visual field showed concentric contraction: in the temporal meridian it was only 75 degrees. Left visual field was 5 degrees wide in every direction, measured with white object $1 \mathrm{~cm}$. square in ordinary daylight, on the Bjerrum screen.

Convergence was 12 degrees of prism, negative convergence -5 degrees.

Ophthalmoscopic examination of media and fundus of each eye was negative. An organic cause for the contraction of the visual fields could not be found, and toxic causes'not traced in the history. Blinding by snow or other strong light was out of the question. Consequently, it appeared to be a case of functional contraction of the visual fields.

There was no evidence in the history. or present state of the patient which could point to a psycho-neurotic condition.

In the text-books three conditions only were mentioned as causing functional contraction, viz., hysteria, neurasthenia and traumatic neurosis.

The last-mentioned was excluded, as there was no trauma in the history of G.'s case; moreover, as an independent farmer he was not likely to develop that disorder.

Neurasthenia can be accompanied by moderate contraction only, a sign of abnormally quick exhaustion (Oppenheim ${ }^{5}$ ). Evidently that did not apply to G.'s case of extreme contraction.

Consequently, hysteria only was left for further consideration. The neurologist who, on my request, examined G., reported :-

I was unable to elicit the presence of any symptoms which could be definitely labelled as psycho-neurotic. On examination he presented no abnormal signs except a certain degree of hyposensitiveness of the palate and soles. As this condition is present in a large proportion of normal people, I do not think that it assists in the diagnosis.

Hysteria, therefore, could be excluded, the more so as functional contraction of the visual field in a case of hysteria always is a sign of a severe form of the disease. Jelgerma writes in this connection $^{6}$ (translated) :

"In hysteria various disorders of the visual organ occur rather frequently. They always are evidence of a rather severe form of hysteria. Concentric contraction of the visual field is the best known symptom and diagnostically of the greatest importance ... so that the patient in some cases has merely left a few degrees round the fovea centralis with conscious perception of visual 
impressions. This form of contraction always is a striking revelation of severe hysteria ... Striking features are ... the lack of symptoms produced. The patients themselves know nothing of $i t$, and it cannot be noticed in their daily lives or in their movements and actions."

The contrast of this description with the case of G. is obvious. There could not be a shadow of doubt that G.'s case was not one of hysteria.

I think it necessary to stress this point because to my knowledge the diagnosis of extreme contraction of the visual fields as a sequel of eyestrain has never been made before. I wish, therefore, to make quite clear the complete exclusion of any alternative diagnosis in this case.

The history shows that this was a case of severe eyestrain of long standing. I knew, by my examinations of G. in 1927 and 1931, that he had suffered from uncorrected astheno-vergence for many years. I had measured the convergence and had found it very low on both occasions.

The only course open, therefore, was to treat the case according to the following diagnosis :

Functional contraction of the visual fields of both eyes and diminished central vision of the left eye (amblyopia), combined with various other symploms of severe eyestrain, caused by astheno-vergence.

The treatment was kinetic.

The ensuing improvement during forty-three daily sittings of kinetic treatment (of ten minutes each) was a model of steadiness. The extremely contracted left field opened up very slowly at first but regularly day by day, until after thirty-six sittings the field was normal. The right eye's field lost its contraction during the same period. Central vision of the left eye increased in acuity, without the help of glasses, from $6 / 9$ to $6 / 4$. Headaches disappeared. G. took to reading again without discomfort. Photophobia was the last symptom to disappear, and G. discarded his dark glasses.

This prompt and complete cure has now lasted more than fifteen years. There never was any recurrence of symptoms.

There are probably many cases of eyestrain connected with functional contraction of the visual fields In the May number, 1930, of the American Journal of Ophthalmology, Rowe and Rowland draw attention to the fact that in a general medical service amongst 1,900 patients, 100 were found to have a marked concentric contraction of the visual fields. In half this number the condition could not be attributed to commonly recognized causes. The paper closes with the remark: "There are 
apparently many cases of marked field contraction in which the condition has not been detected."

I suggest that in many such cases the cause may be asthenovergence.

\section{Discussion}

The two cases of field contraction described in this paper can be considered as extreme cases representative of a large group. My subject, however, is not what they are representative of, but that they are typical forms of field contraction for which there is yet no name and therefore no apparent therapy. In the literature no mention is made of this form of field contraction (except once by me). It probably becomes grouped, unwittingly and wrongly, with other groups of functional field contraction for which there is given an accurate diagnosis, but the kind of field contraction under consideration here has not yet been recognized as a clinical entity. Therefore there exists no therapy, and as the condition is progressive diminution of sight, the prognosis must appear bad. This is what the practical ophthalmologist is faced with in cases of this type, unless he realizes its meaning in di-ophthalmology. As soon as the condition is recognized as a bi-foveal matter, showing its main disturbances in the visual field, then the position is clear and therapy rational and effective.

\section{Case III}

Another typical case, this time not of peripheral but of central amblyopia, once more emphasizes the importance of di-ophthalmology.

A girl, aged 16 years, had been prescribed -1.0D sph. for each eye. She was studying the piano but was told by the ophthalmologist to give up music and all study, as there was something very wrong with her eyes, which was progressive. The parents were alarmed, and May 30, 1945, came to me for a further opinion.

The history revealed severe headaches during the day-time, and also photophobia. Moving pictures irritated the eyes and caused bad headaches. Often the eyes were bloodshot. Vision, of late years, had become gradually worse. It was thought that the patient had become more and more myopic. She herself, dejected and upset, at first emphatically refused to undergo the proposed kinetic treatment.

I found visual acuity right eye $6 / 18$, with correction (-1.0D. sph.) $6 / 12$, visual acuity left eye $6 / 18$, with correction (-1.0D. sph.) 6/12. Negligible refractive error. Convergence 16 degrees of 
prism (principal angle). Negative convergence -5 . As this clearly was a case of astheno-vergence causing eyestrain, kinetic treatment was instituted the next day. After twenty-one daily sittings of the treatment (about ten minutes each) the convergence ranged to 91 degrees of prism.

Visual acuity of each eye (without correction) had become $6 / 5$. During the treatment the girl had become bright and lively and resumed her piano lessons. Three months afterwards the visual acuity of each eye was 6/4 (without correction) and her eyes caused no trouble. With my usual precautionary measures, viz., a few sittings of kinetic treatment half a year after the cure and again one or two sittings a year later, the normal condition of the eyes remained stable.

\section{Discussion}

This therefore is another case representative of a great group and typical of a kind of condition which is not yet recognized in ophthalmology as a clinical entity, but is known to those who are versed in the facts of di-ophthalmology, which is based on the bi-fovea and its correlate convergence, the kinetic principle of bi-foveal vision.

\section{Summary}

These three cases represent a form of disturbance of field or central vision, or both, which if one does not grasp the importance of kinetic factors as revealed by the study of the bi-fovea and its correlate, convergence, must lead to a sombre prognosis. With kinetic treatment, however, which superficially would seem to affect adduction, abduction and bi-foveal fusion only, these cases are effectively cured both of peripheral field limitation and central visual failure. They emphasize the broadness of the conceptions aligned under the title of di-ophthalmology.

\section{REFERENCES}

1. Stutterheim, N. A. (1931).-Indications for the Kinetic Treatment of the Eyes. Monograph Supplement, Brit: Jl. Ophthal., Vol. XV.

2. -__ (1932). - The Convergence of Human Binocular Vision. Brit. Jl. Ophthal., Vol. XVI, p. 20.

3. (1937).-Eyestrain and Convergence. London: H. K. Lewis \& Co.

4. Pp. 1-16. London: H. K. Lewis \& Co. Pp. 5-9.

5. OpPenheim, H. (1923). - Lehrbuch der Nervenkrankheiten. Berlin : S. Karger. P. 1771 .

6. Jergersma, G. (1926).-Leerboek der Psychiatrie. Amsterdam : Groesbeek en Nyhoff. P. 117. 